\title{
Integrating 3D Printing Technologies into Architectural Education as Design Tools
}

\author{
Hemza Boumaraf ${ }^{a^{*}}$, Mehmet İnceoğlu ${ }^{b}$ \\ ${ }^{a}$ Faculty of Architecture, Iki Eylul Campus, Anadolu University, Eskişehir 26555, Turkey \\ ${ }^{b}$ Faculty of Architecture, Iki Eylul Campus, Eskişehir Technical University, Eskişehir 26555, Turkey
}

\begin{abstract}
3D printing technology offers the chance to produce very small-scale, complex forms that could help to improve educational materials for architectural design. In this age of technological advances, architectural education needs to integrate modern teaching methods that could enhance students' visual perception. This research thus examined the impact of computational design modeling and 3D printing technology on the spatial cognition of architecture students. It starts with the premise that the use of the 3D printed models will support design logic and improve the deep understanding of spatial perception among students. Thirty architecture students were asked about a designed project realized for the purpose of this study. They were presented both a project designed via computer modeling software and a printed model of the same project. The outcomes indicate that the use of $3 \mathrm{D}$ printing gave better results in the development of students' spatial abilities. The findings also confirm that adopting this technology in the development of teaching tools will enhance students' spatial perception and extend beyond the seamless materialization of the digital model which can continuously inform design ideation through emerging perception qualities.
\end{abstract}

\section{Keywords:}

3D Printing;

Computing Design;

Spatial Perception;

Visualization;

Architectural Education.

\section{Article History:}

$\begin{array}{llll}\text { Received: } & 01 & \text { November } & 2019 \\ \text { Accepted: } & 15 & \text { February } & 2020 \\ \text { Published: } & 01 & \text { April } & 2020\end{array}$

\section{1- Introduction}

The use of 3D models in various fields like architecture, urban planning, education, communication, and natural resource management is becoming more common [1-2]. It is improving quickly toward presenting more realistic models which enhance user understanding of spatial perception in different areas and can be used as an effective communication tool among students [3]. Today the focus is more on visualization development through representing designs using different techniques and technologies.

Although the use of 3D printing is still in its early years in all disciplines, the potential benefits seem to be driving the technology forward [4]. There is a wide range of views about where this technology altering. Among recent technological developments, 3D printing has been deemed as one of the most promising. Karlgraad called 3D printing the transformative technology of the 2015-2025 period [5]. The increase seen in 3D printer use today is aided by the easy access to this type of technology and on account of the aim of altering the production chain of design, modeling, and manufacturing [6].

3D modeling techniques have emerged as important core competencies, and innovations developed through the widespread application of 3D technologies have led to breakthroughs in medical science and machinery automation, and even in education [7-8]. As designers, manufacturers, and consumers look for ways to address this growing demand, many are considering the possibilities of 3D printing. Due to 3D printing's flexibility and relative mobility, it is speculated that it could help to meet the growing demands of the developing world. It could also help students. We

\footnotetext{
*CONTACT: Boumaraf.hemza@gmail.com

DOI: http://dx.doi.org/10.28991/esj-2020-01211
}

(C) 2020 by the authors. Licensee ESJ, Italy. This is an open access article under the terms and conditions of the Creative Commons Attribution (CC-BY) license (https://creativecommons.org/licenses/by/4.0/). 
should always keep in mind that almost every aspect of such models is driven by software which is entirely surfaceoriented in its underlying mathematics, the very same surface mathematics which is, of course, now also being used in the machines, making possible new output technologies such as 3D printing, milling, or laser cutting [9]. Accordingly, this study focuses on the use of both computing design and 3D printing technology to investigate students' spatial cognition. A project example designed using Archicad as computer software and a 3D printed model of the same project example were compared to see the effects of the two techniques on students' spatial cognition.

\section{2- From Computing Design to 3D Printing}

3D visualization on computers enhances the user's understanding of the spatial and physical environments which are concerned with different interaction aspects. Recently, most of the 3D models presented in 2D have constraints. In addition, the methods of teaching with 3D modeling depend on the use of computer programs to guide students in the construction of spatial perception. However, this method could not effectively support students to attain the needed results, especially if the projects are complex and detailed. With the development of the technology, however, 3D printing has been selected as the most effective method for producing the same versions of designs directly from a digital source [10]. It is a method of additive production in which material layers are placed upon each other to build an object. Several design technologies have been developed in this domain. Z Corporation has stated that the increasing popularization of these technologies has had a gradual impact on education [4]. Huang and Tien-Chi mentioned that the popularization of computer-aided design and computer-aided manufacturing (CAD-CAM) and the implementation of computer numerical controls (CNC) and robotic arms has significantly improved architectural design education [11]. On the other hand, as technologies have become increasingly reasonable, technologies for rapid modeling and customization have begun to receive increased attention as well.

The technology for printing physical 3D objects from digital data was first developed by Charles Hull in 1984 [4]. He named the technique stereo lithography and obtained a patent in 1986. In 1993 the Massachusetts Institute of Technology (MIT) patented another technology, named "3-dimensional printing techniques," which is similar to the inkjet technology used in 2D printers [12]. In 2005, Z Corp launched a breakthrough product, named Spectrum Z510, which was the first high-definition color 3D printer on the market. Huang and Tien-Chi believe that the broad and deep impact of 3D printing technology in education has driven the need to help students develop independent spatial condition [11].

3D printing is one of the leading subjects that could benefit from considering design issues. Few studies in different research fields are carried out using 3D printing technology and they have many limitations [13]. We can also see that the resources necessary for fabrication in architectural design are artificial intelligence software and equipment for digital manufacturing. Digital development and fabrication enhance contemporary architectural design and offer remarkable potential for a direct connection between the life cycle of a building's concept, manufacturing, and development phases. Design and fabrication processes are simplified when structural materials and parts can be assembled directly from concept drawings, transported to the site, and installed to shape the entire building. Fabrication applications involve various methods, such as structural steel production, pipe welding, product prototyping, panel design, and manufacturing [14]. Since 2005, significantly larger 3D printers have become available, and the costs have also decreased dramatically, mainly due to competition among 3D printing service providers. For example, a recent survey shows that the number of components manufactured with additive manufacturing processes has risen sharply in the last few years [15]. Subsequently, this study describes an architectural design studio experiment developed with the aim of exploring the combined use of computer software and 3D printed model of the same design to test students' spatial cognition. The emergence of additive manufacturing and 3D printing technologies is introducing new skills and opportunities for new teaching practices in a range of subjects and educational settings.

\section{3- 3D Printing in Educational Context}

Originally developed in the 1980s in a large number of fields and markets, additive technology is best known through the example of 3D printing, though bio printing also derives from this technology, allowing the development of materials triggered by time, light, water, biological behavior, or other energy activation to be essential processes for achieving desired forms [16]. The integration of this technology with its different techniques into the area of education may offer new opportunities and teaching practices in various subjects. As a reflection of this, many studies have investigated these possibilities within many disciplines, but several steps are still lacking to reach the expected results. Berman notes that technologies for rapid modeling have begun to receive increasing attention in the educational context with the aim of helping students to learn [17]. The increasing popularization of 3D printing technology has had a gradual impact on industrial hardware and software, driving changes to educational training operations as well [6-18]. Teaching 3D modeling using 3D printing technology could facilitate learning in fields ranging from engineering to design to art [19]. While these technologies continue to progress, there are concerns that the slow development of education and skills may prevent the adoption of technology on a larger scale [20]. 
In universities, 3D printing is notably used in the sciences, where students' learning process is supported by the creation of 3D models for experimental tests of materials' mechanical properties $[21,26]$. It is also used for studying special settings like visual perception and spatial visualization [22]. Improving the spatial visualization ability of architecture students is a challenge for educational researchers. Many researchers have demonstrated that teaching with computer-generated design visualizations can provide learners with adequate experiences for the development of their spatial cognition [23-24]. Learners' spatial skills are the most important and significant predictor of success in manipulating objects and interacting with computer-aided design [25]. 3D printed material test models in engineering curricula have been shown to be acceptable for this purpose. Across various universities, technical experiments have been integrated into undergraduate research courses [26-27]. Katsioloudis proposed the use of 3D printed models as teaching aids for engineering and spatial ability, and assumed that they could help to enhance students' understanding of modeling tasks [28]. Furthermore, students could gain a better understanding of visual data from 3D printed models than from other visualization techniques [29-30]. Few studies have examined the effects of computing design and 3D printing as teaching materials on ability [28]. Therefore, this study explores the impact of integrating 3D printing into 3D modeling techniques on learning outcomes among students of architecture with different spatial perception.

\section{4- Experimental Study}

The aim of this study was to investigate how students' perception improves from working with 3D computing and stereoscopic representations. We started with the hypothesis that the two different representations of the same realworld projects can deliver very different sets of spatial information. The overall research objective of the study is to consider the potential of $3 \mathrm{D}$ printing to create novel performative uses of design tools in architectural education.

\section{4-1- Design Process}

We designed a project to be used as a research case study. The project is a small exhibition hall of $10 \times 10 \mathrm{~m}$ designed with Archicad computing software (Figure 1). The characteristics of an exhibition hall are appropriate for a study which focuses on spatial cognition and visual perception. The project was designed to be simple and to focus more on the research outcomes. However, some details have been added like irregular openings, exterior structure, and complex roof form to make spatial perception progress and to obtain different results from both computing design and 3D printed model (Figure 2).
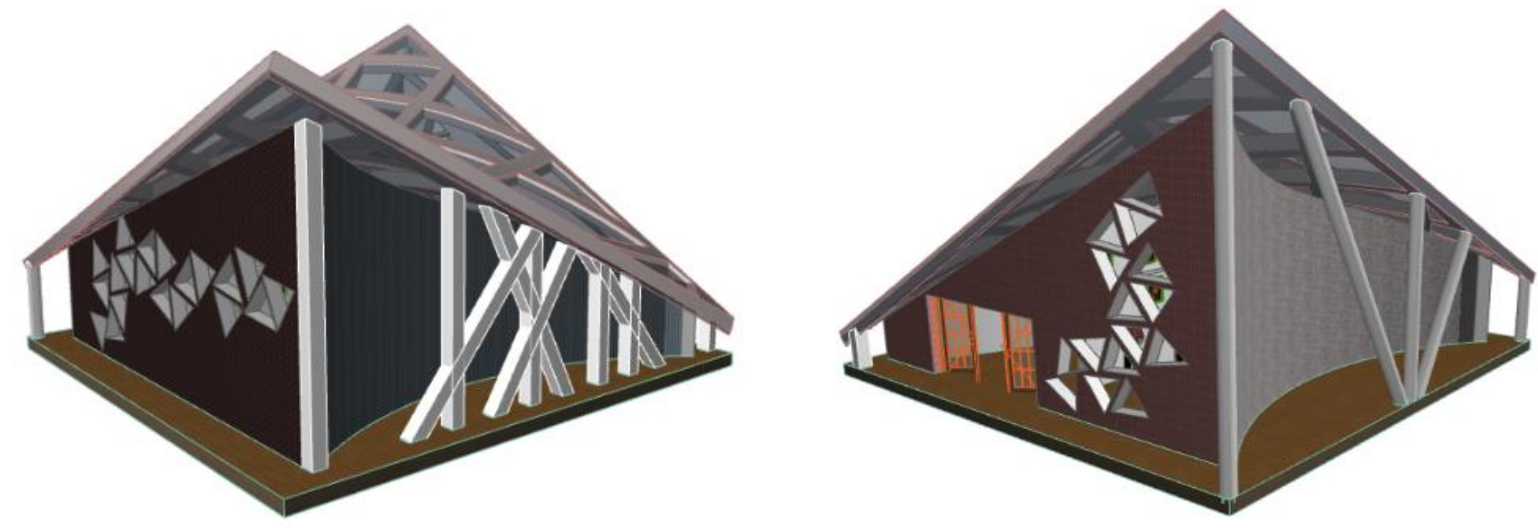

Figure 1. General form of the exhibition hall designed via Archicad.
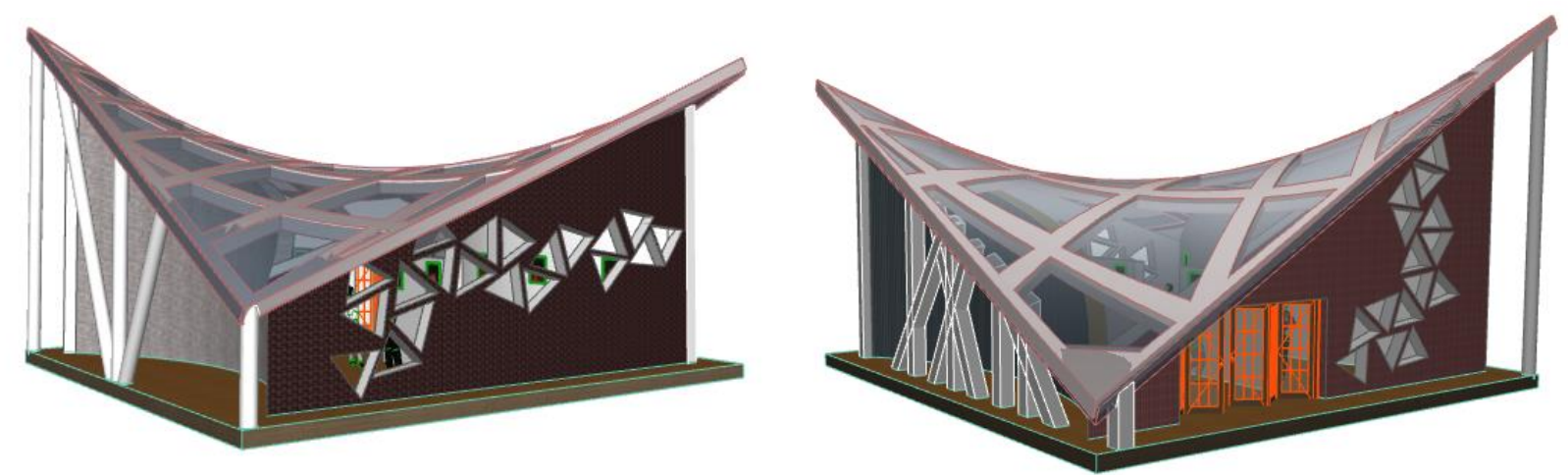

Figure 2. Details added within the project (Openings, structure and roof form). 
As long as the 3D printers did not develop the ability to use specific textures and for the aim of making the design as clear as possible, many examples were created with different textures and colors tones (Figure 3).
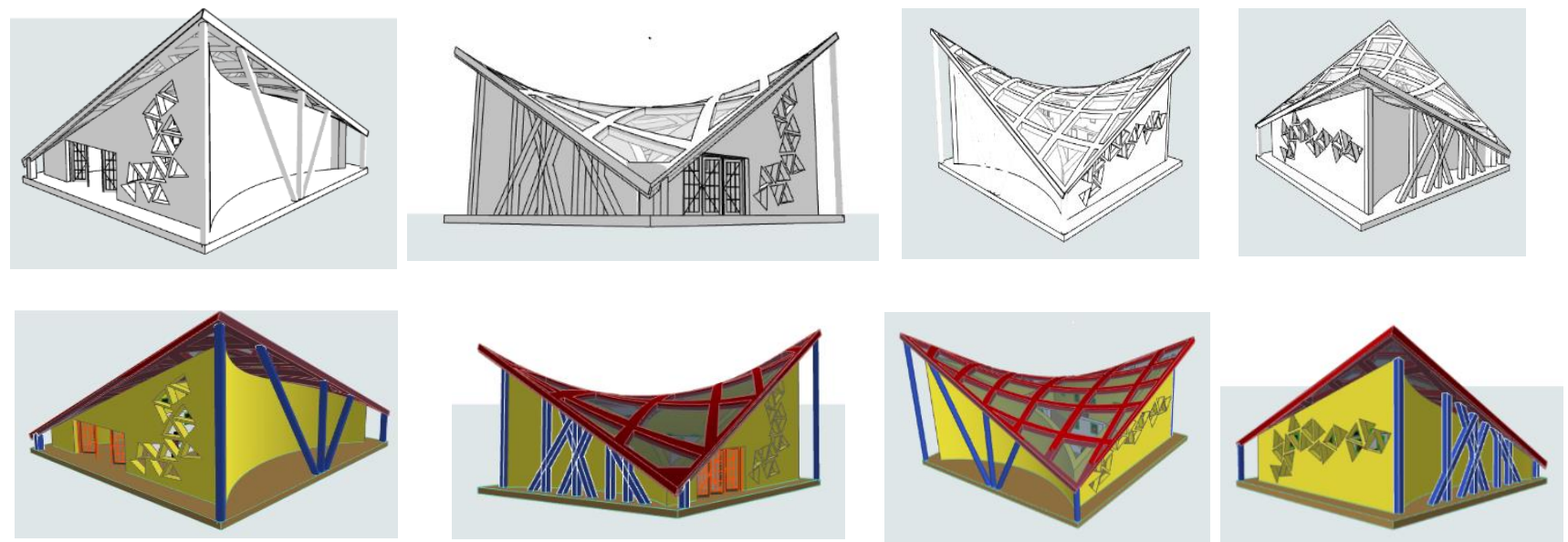

Figure 3. Uses of different textures and colours tones on the project.

After finishing the design in Archicad, the project was printed with an Ultimate 3D printer using three basic colors, red, blue, and yellow, at 1/100 scale. The different colors were used to differentiate the details, aiming for clear spatial visualization. The print time was about nine hours and thirty-five minutes. The result was a clear printed model representing the design project. This provided an indication of what to expect during fabrication at real size with materials defined in the micro-dimension. However, the limitations in the achievable curvature and resolution on described research prevented the adoption of such techniques considering the level of detail and complexity of the model. In order to obtain the desired finishing surface, additive 3D printing methods were also discarded (Figure 4).
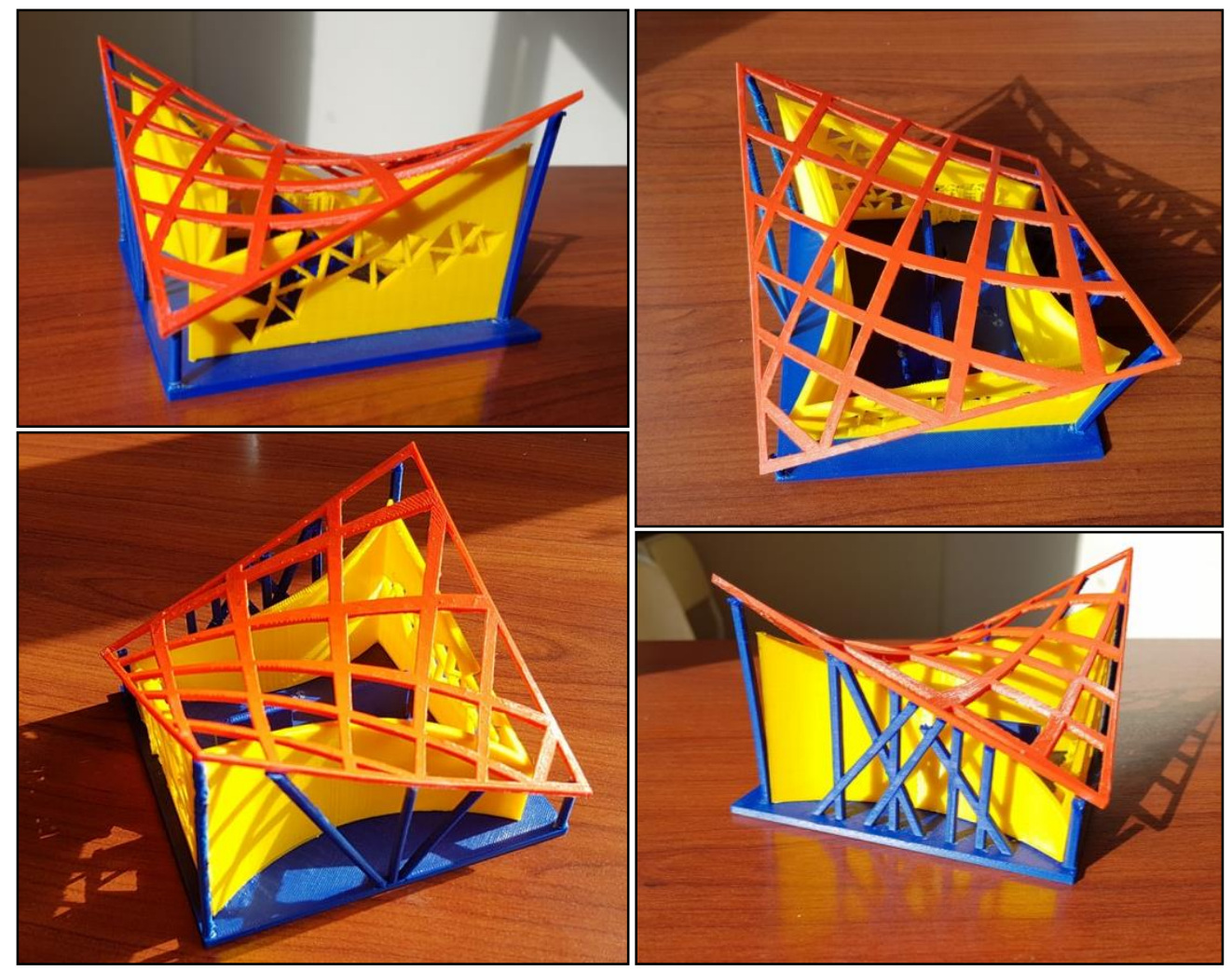

Figure 4. 3D printed model of the exhibition form via Ultimate 3D printer.

\section{4-2- Participants and Data Collection}

A group of thirty students (18 male and 12 female) were randomly recruited from the Architecture Department of Anadolu University in Eskisehir, Turkey to answer a questionnaire. The students ranged in age between 19 and 21 
(first and second year). Gender composition was not a criterion in this study, because we focused on general outcomes more than differences in perception. A quantitative study was designed to perform the analysis of their spatial cognition. Questions were arranged according to the model's characteristics, general form, wall openings, structure, and roof form. The possible answers ranged from "very clear" to "not clear.".

The first step was to show the students the project designed with Archicad from different perspectives. Then the students were presented with the printed 3D model and they had the chance to hold it, rotate it, and examine it. After that, they answered a questionnaire containing ten questions about their perception and spatial cognition based on both computer-aided and 3D printed models. The questions were asked about the project as a whole and the details like openings, structure, and roof form to specify the enhancement outcomes. This gave them the opportunity to understand the project and to compare their perception derived from both models. The collected data were analyzed to assess the effect of 3D printing in enhancing spatial cognition and to find answers to the research questions: Is there any difference in spatial perception as measured through 3D computer-aided design and 3D printed models? Does 3D printing aid spatial cognition more than computing design?

\section{5- Results and Discussion}

The main purpose of this study was to determine the contribution of 3D printing to students' spatial perception. In particular, the study compared the use of two different types of 3D modeling (design via computer software and a 3D printed model). To facilitate the discussion of the results, some terms have been abbreviated: GF (general form of the model), DS (details and structure), RF (roof form), NS (number of students), CD (computer design), 3DP (3D printed model). See Table 1. The study involves the practical application of 3D printing techniques through rapid prototyping and usable component assembly, as well as 3D visualizations and experiments for checking model properties.

Table 1. Results of the questionnaire (students' answers).

\begin{tabular}{ccccccc}
\hline \multirow{2}{*}{ Model } & \multicolumn{2}{c}{ Very clear } & \multicolumn{2}{c}{ Partially clear } & \multicolumn{2}{c}{ Not clear } \\
\cline { 2 - 7 } & CD & 3DP & CD & 3DP & CD & 3DP \\
\hline GF & 20 & 27 & 8 & 2 & 2 & 1 NS \\
DS & 12 & 25 & 10 & 3 & 8 & 2 NS \\
RF & 7 & 27 & 10 & 2 & 13 & 1 NS \\
\hline
\end{tabular}

It was found that the 3D printed model and 3D computer design both provided a clear visualization of the whole design's general form (GF) (Graf. 1). However, the majority of the students declared that their perception of the project's details and structure (DS) were clearer in the 3D printed model (Graf. 2). The participated students' spatial cognition of roof form (RF) was also strongly improved by the 3D printing model (Graf. 3). The important advantage of using 3D printing as a learning aid is that the opportunity to manipulate a physical object often brought into focus new elements for assessment that cannot be seen when using computer design (CD) alone.
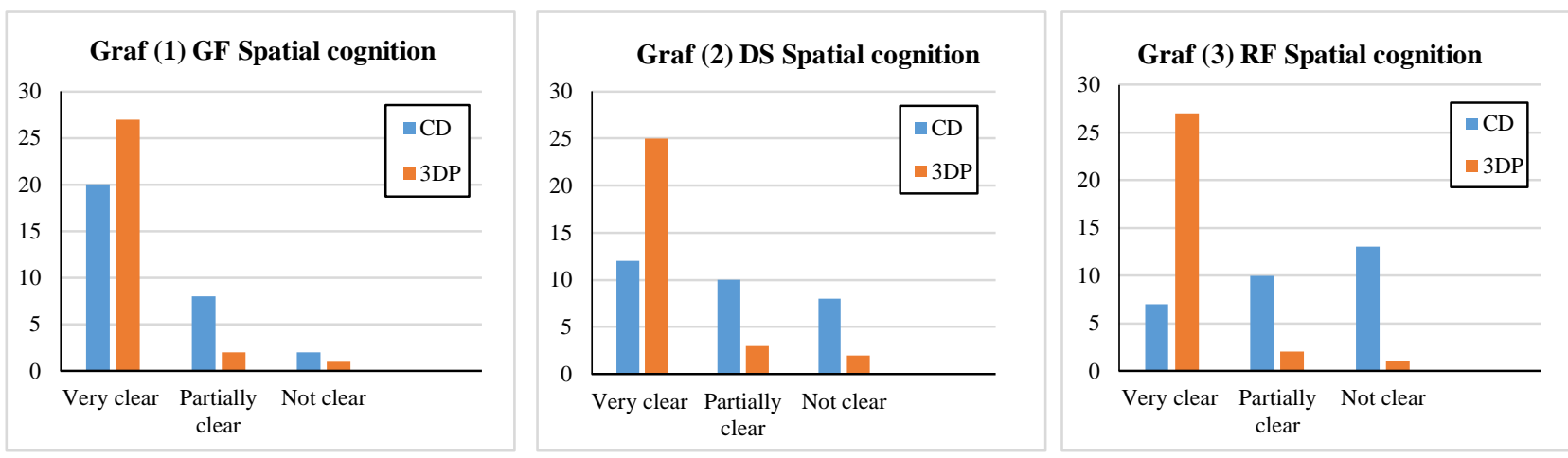

Figure 5. Descriptive results of the CD and 3DP spatial perception.

Some questions aimed to investigate the positive effects of 3D printing on the students' spatial perception and to confirm whether the students agreed that the 3D printing technology enhanced it more than computer-designed models. The results show that almost all the students agreed that 3D printing positively affected their perception (Tables 2 and 3). In particular, it was found that the use of 3DP had a positive impact in relation to understanding, interest, and cognition. They clearly understood that the project was an exhibition hall after examining the 3D printed model, while many of them did not realize this when viewing the project via Archicad. It should be mentioned that $90 \%$ of the students noted that 3D printing strongly affected their perception and spatial cognition, $10 \%$ answered that 
they were partially affected, and $96.66 \%$ agreed that this technology is needed for their learning (Graf.4 and 5). Educational tools could be 3D printed to help educators in architecture.

Table 2. Positive effect of 3D printed model on students' spatial cognition.

\begin{tabular}{cccc}
\hline & Strongly affected & Partially affected & No effect \\
\hline 3DP Positive effect & 27 NS $(90 \%)$ & 3 NS $(10 \%)$ & 0 NS $(0 \%)$ \\
\hline
\end{tabular}

Table 3. 3DP enhances spatial cognition more than CD (Students agreement).

\begin{tabular}{cccc}
\hline & Strongly agree & Partially agree & Do not agree \\
\hline 3DP $>$ CD & 29 NS $(96.66 \%)$ & 1 NS $(3.33 \%)$ & 0 NS $(0 \%)$ \\
\hline
\end{tabular}

Interestingly, the results show some differences in using CD and 3DP to attain clear spatial cognition. First of all, there was a significant difference in the perception of RF, indicating that 3DP is more beneficial for students with very clear perception (Graf. 6). The same was found concerning the cognition of complex details like openings and structure. However, the results of using both CD and 3DP as visualization methods for perception of the whole form were almost identical (Graf. 7 and 8). This suggests that continuous improvement brought on by 3DP cognitive experience using printed models is needed for understanding complex details of spatial visualization. Students will need such technology that helps them to interpret complex project forms, especially during the development of designs. Perhaps beneficial from another pedagogical viewpoint is the integration of 3DP as it can provide opportunities to practice different learning strengths, like experiential learning and performance. The architectural disciplines resulting from the incorporation of these technologies into teaching can be identified through promoting learning, developing skills, and student participation, while increasing the involvement and dedication of teachers.

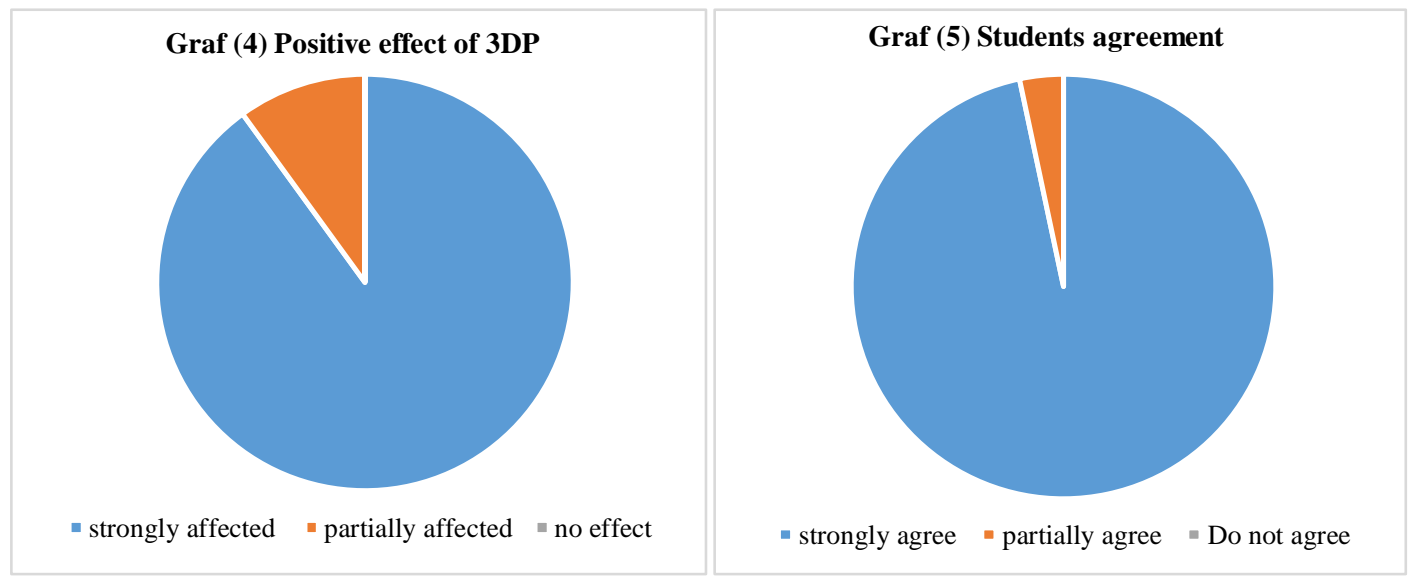

Figure 6. 3DP positive effects on students' spatial perception.

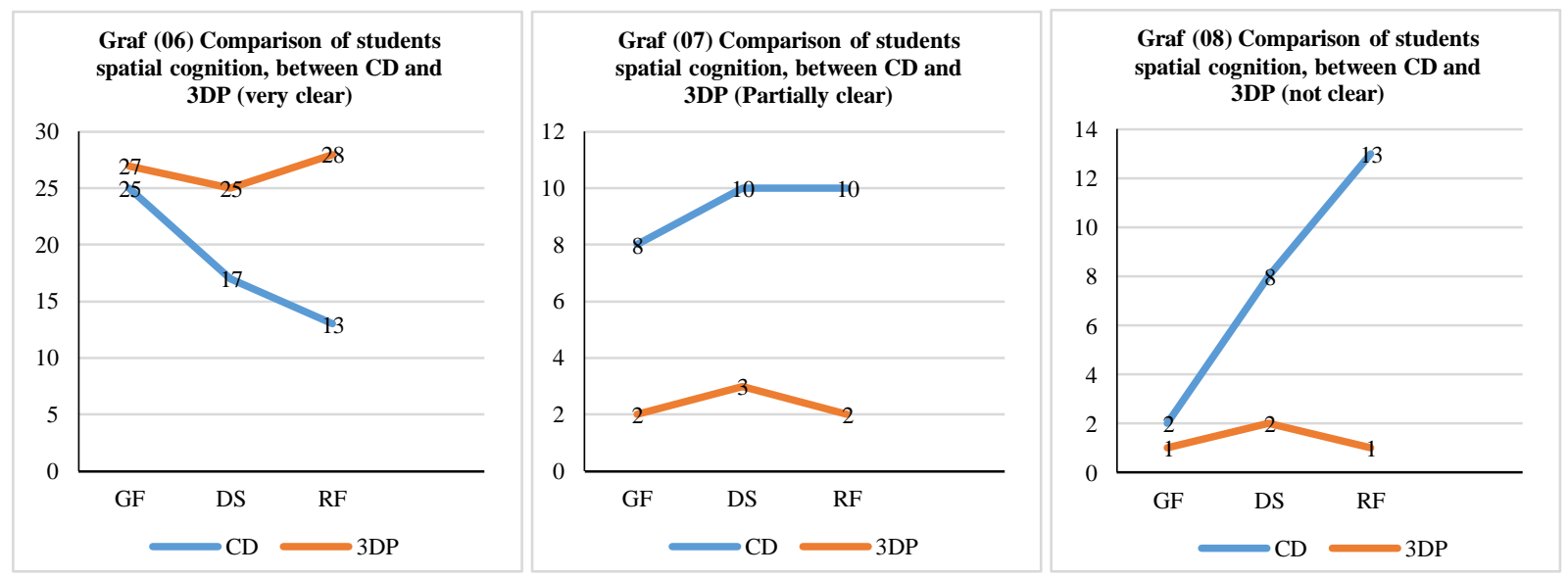

Figure 7. Comparison of CD and 3DP in Students' spatial cognition. 
The most important aspect of this study's findings is the fact that 3DP encouraged the students to interpret the model more flexibly than CD. The design system allows for configuration adjustments to be made even if the form is exactly the same, because 3DP allows variation within certain limits. Therefore, since 3DP is digital, model production depends on exact parameters and thus each component of the model can be printed with measurements that are similar but not necessarily identical.

The modernization and transformation of education provide resources for self-directed learning. Therefore, a better understanding is needed of how to acquire 3DP skills outside the traditional education program, and how to adapt learning from informal and formal education. While developing the theoretical part to better support this research, it became clear that there is a lack of research related to 3D models and their ability to enhance spatial cognition and perception. This research can help in understanding the different types of 3D modeling technology that could be used in education. With the many design technologies available, students have the chance to design almost any model in a very short time. This study provides results related to the commonly used method of computer modeling. It is confirmed that 3D printing technology gives students a better understanding of projects and models; however, more research in the same area is needed.

\section{6- Conclusion}

It is important to know that 3D printing technology is still in its early stages. It is used in different applications which could help to accomplish and facilitate some educational targets. We believe that 3D printing can support spatial perception for students better than computer-aided 3D modeling. The printed models can be very beneficial for architectural design and urban planning, particularly concerning spatial experiences. In architectural education the creative advantage of using 3D printing is the ease with which special shapes can be made. This eliminates the boundaries students normally must comply. We made use of computational modeling as well as technologies such as $3 \mathrm{D}$ printing. In addition, we learned how those techniques can be integrated into architectural education through an experimental design with students of architecture. This study investigated the contribution of 3D printing technology as a teaching model to explore students' spatial perception. The results indicate that architectural design education can benefit from the integration of 3D printing into the learning framework. It was found that 3D printing effectively enhances learners' spatial cognition and perception and could be a useful teaching tool. The use of both visualization techniques (CD, 3D) generates a unique perceptual experience that broadens students' understanding of design projects, contributing to their cognitive achievements. The findings have also shown that the integration of 3D printing technology into the teaching process is a means of improving students' perception. However, these experiments are still very limited in number and results, in the sense that they do not fully explore the potential of the technology and its impact on the way we design and make buildings.

\section{7- Acknowledgments}

We wish to record our profound thanks to Prof. Dr Leyla Y. Tokman from Eskisehir Technical University for her inspiring guidance to bring this research into fruition. Besides that, we would like to thank to Dr. Burak EVIRGEN from the Civil engineering department of Anadolu university and the 3DHANE company in Ankara for their support during the model's printing.

\section{8- Conflict of Interest}

The author declares that there is no conflict of interests regarding the publication of this manuscript. In addition, the ethical issues, including plagiarism, informed consent, misconduct, data fabrication and/or falsification, double publication and/or submission, and redundancies have been completely observed by the authors.

\section{9- References}

[1] Stoter, J., Brink, L. v/d, Vosselman, G., Goos, J., Zlatanova, S., Verbree E., Klooster, R., Berlo, L. van, Vestjens, G., Reuvers, M. and Thorn, S, "A generic approach for 3D SDI in the Netherlands", In: Proceedings of the Joint ISPRS Workshop on 3D City Modelling\&Applications and the 6th 3D GeoInfo Conference, (2011), Wuhan, China.

[2] Zlatanova, Sisi, Laure Itard, Mahmud Shahrear Kibria, and Machiel Van Dorst. "A user requirements study of digital 3D models for urban renewal." open house international 35, no. 3 (2010): 37-46.

[3] Rapidtoday. GIS 3d Printing Made Easier with Software (2012). Available online: http://www.rapidtoday.com/GIS-3DPrinting.html (accessed on 10 December 2018).

[4] Z Corporation. "3D Printing Technology: Fast, Affordable and Uniquely Versatile". 2st edition. Rock Hill: USA, Z Corp pri vet company, (2005).

[5] Karlgraad, R. 3D printing will revive American manufacturing. Forbes,. Available online: http://www.forbes.com/sites/richkarlgaard/2011/06/23/3d-printing-will-revive-american-manufacturing/ (accessed on 19 December 2018). 
[6] Rayna, Thierry, Ludmila Striukova, and John Darlington. "Co-Creation and User Innovation: The Role of Online 3D Printing Platforms." Journal of Engineering and Technology Management 37 (July 2015): 90-102. doi:10.1016/j.jengtecman.2015.07.002.

[7] Kostakis, Vasilis, Vasilis Niaros, and Christos Giotitsas. "Open Source 3D Printing as a Means of Learning: An Educational Experiment in Two High Schools in Greece." Telematics and Informatics 32, no. 1 (February 2015): 118-128. doi:10.1016/j.tele.2014.05.001.

[8] Kostakis, Vasilis, and Marios Papachristou. "Commons-Based Peer Production and Digital Fabrication: The Case of a RepRapBased, Lego-Built 3D Printing-Milling Machine." Telematics and Informatics 31, no. 3 (August 2014): $434-443$. doi:10.1016/j.tele.2013.09.006.

[9] Kolarevic, B and Klinger, K, Manufacturing Material Effects. Rethinking Design and Making in Architecture (2008), Routledge, 1st edition. New York.

[10] Khorram Niaki, Mojtaba, and Fabio Nonino. "Additive Manufacturing Management: a Review and Future Research Agenda." International Journal of Production Research 55, no. 5 (September 2, 2016): 1419-1439. doi:10.1080/00207543.2016.1229064.

[11] Huang, Tien-Chi, and Chun-Yu Lin. "From 3D Modeling to 3D Printing: Development of a Differentiated Spatial Ability Teaching Model.” Telematics and Informatics 34, no. 2 (May 2017): 604-613. doi:10.1016/j.tele.2016.10.005.

[12] Baynes, S., and M. Steele. "3D Printing and the Construction Industry." Canada Mortgage and Housing Corporation (CMHC) 3 (2015).

[13] Mellor, Stephen, Liang Hao, and David Zhang. "Additive Manufacturing: A Framework for Implementation.” International Journal of Production Economics 149 (March 2014): 194-201. doi:10.1016/j.ijpe.2013.07.008.

[14] Menges, Achim, Tobias Schwinn, and Oliver David Krieg. “Advancing Wood Architecture.” Edited by Achim Menges, Tobias Schwinn, and Oliver David Krieg (July 22, 2016). doi:10.4324/9781315678825.

[15] Wohlers, TT. Wohlers Report: 3d printing and additive manufacturing state of the industry, Wohlers Associates, Fort Collins (2017). ISBN 978-0-9913332-5-7.

[16] Papadopoulou, AP, Laucks, JL and Tibbits, ST. General Principles for Programming Material, in Tibbits, ST (eds), Active Matter (2017), MIT Press, Cambridge, MA, pp. 125-142.

[17] Berman, Barry. “3-D Printing: The New Industrial Revolution.” Business Horizons 55, no. 2 (March 2012 ): 155-162. doi:10.1016/j.bushor.2011.11.003.

[18] Oropallo, William, and Les A. Piegl. “Ten Challenges in 3D Printing.” Engineering with Computers 32, no. 1 (June 12, 2015): 135-148. doi:10.1007/s00366-015-0407-0.

[19] Casas, Lluís, and Eugènia Estop. "Virtual and Printed 3D Models for Teaching Crystal Symmetry and Point Groups.” Journal of Chemical Education 92, no. 8 (May 5, 2015): 1338-1343. doi:10.1021/acs.jchemed.5b00147.

[20] European Commission. Additive Manufacturing in FP7 and Horizon 2020: Report from the EC Workshop on Additive Manufacturing (2014), Brussels, Belgium.

[21] P. McGahern, F. Bosch, D. Poli, “Enhancing Learning Using 3D Printing.” The American Biology Teacher 77, no. 5 (May 2015): 376-377. doi:10.1525/abt.2015.77.5.9.

[22] Buehler, Erin, Shaun K. Kane, and Amy Hurst. "ABC and 3D." Proceedings of the 16th International ACM SIGACCESS Conference on Computers \& Accessibility - ASSETS '14 (2014). doi:10.1145/2661334.2661365.

[23] Kwon, Oh Nam. "Fostering Spatial Visualization Ability through Web-Based Virtual-Reality Program and Paper-Based Program.” Lecture Notes in Computer Science (2003): 701-706. doi:10.1007/3-540-45036-x_78.

[24] Woolf, B., Romoser, M., Bergeron, D., \& Fisher, D. “Tutoring 3-dimensional visual skills: Dynamic adaptation to cognitive level”. In Proceedings of the 11th International Conference on Artificial Intelligence in Education, Sydney, Australia, (2003).

[25] Norman, Kent L. "Spatial Visualization-A Gateway to Computer-Based Technology." Journal of Special Education Technology 12, no. 3 (March 1994): 195-206. doi:10.1177/016264349401200303.

[26] Ngo, Tuan D., Alireza Kashani, Gabriele Imbalzano, Kate T.Q. Nguyen, and David Hui. "Additive Manufacturing (3D Printing): A Review of Materials, Methods, Applications and Challenges." Composites Part B: Engineering 143 (June 2018): 172-196. doi:10.1016/j.compositesb.2018.02.012.

[27] Ford, Simon, and Tim Minshall. "Invited Review Article: Where and How 3D Printing Is Used in Teaching and Education." Additive Manufacturing 25 (January 2019): 131-150. doi:10.1016/j.addma.2018.10.028.

[28] Katsioloudis, Petros, Vukica Jovanovic, and Mildred Jones. "A Comparative Analysis of Spatial Visualization Ability and Drafting Models for Industrial and Technology Education Students.” Journal of Technology Education 26, no. 1 (September 1, 2014): 88-101. doi:10.21061/jte.v26i1.a.6. 
[29] Morán, Samuel, Ramón Rubio, Ramón Gallego, Javier Suárez, and Santiago Martín. "Proposal of Interactive Applications to Enhance Student's Spatial Perception.” Computers \& Education 50, no. 3 (April 2008): 772-786. doi:10.1016/j.compedu.2006.08.009.

[30] Passig, David, David Tzuriel, and Ganit Eshel-Kedmi. "Improving children's cognitive modifiability by dynamic assessment in 3D Immersive Virtual Reality environments." Computers \& Education $95 \quad$ (2016): 296-308. doi:10.1016/j.compedu.2016.01.009. 